\title{
Constraints on droplet growth in radiatively cooled stratocumulus clouds
}

\author{
P. H. Austin \\ Atmospheric Sciences Programme, Department of Geography, University of British Columbia, \\ Vancouver, Canada
}

S. Siems

Department of Mathematics, Monash University, Clayton, Victoria, Australia

Y. Wang

Atmospheric Sciences Programme, Department of Geography, University of British Columbia, Vancouver, Canada

\begin{abstract}
.
Radiative cooling near the top of a layer cloud plays a dominant role in droplet condensation growth. The impact of this cooling on the evolution of small droplets and the formation of precipitation-sized drops is calculated using a microphysical model that includes radiatively driven condensation and coalescence. The cloud top radiative environment used for these calculations is determined using a mixedlayer model of a marine stratocumulus cloud with a subsiding, radiatively cooled inversion. Calculations of the radiatively driven equilibrium supersaturation show that net long wave emission by cloud droplets produces supersaturations below $0.04 \%$ for typical nocturnal conditions. While supersaturations as low as this will force evaporation for droplets smaller than $\approx 5 \mu \mathrm{m}$, radiatively enhanced growth for larger droplets can reduce the time required to produce precipitation-sized particles by a factor of $2-4$, compared with droplets in a quiescent cloud without flux divergence. The impact of this radiative enhancement on the acceleration of coalescence is equivalent to that produced in updrafts of $0.1-0.5 \mathrm{~m} \mathrm{~s}^{-1}$, and varies linearly with the total emitted flux (the "radiative exchange").
\end{abstract}

\section{Introduction}

L ong wave cooling at the top of the cloud-capped boundary layer can exert a controlling influence on layer dynamics and cloud microphysics. Observations and models show that stratocumulus clouds beneath a dry inversion are subjected to cooling rates of $7-10 \mathrm{~K} \mathrm{hr}^{-1}$ [Caughey and Kitchen, 1984], with substantially larger flux divergences possible close to the top of thick clouds [Davies and Alves, 1989]. The cooling is due primarily to emission from droplets, and this emission allows larger cloud droplets to shed heat efficiently and grow at rates more than an order of magnitude greater than those experienced in the center of a quiescent cloud [Roach, 1976; Barkstrom, 1978]. The growing droplets deplete the available vapor and reduce the ambient supersaturation as they cool the air; these two opposing influences force the cloud parcel to its equilibrium su-

Copyright 1995 by the American Geophysical Union.

Paper number 95JD01268.

0148-0227/95/95JD-01268\$05.00 persaturation, which is determined by the droplet size distribution, the net flux divergence, and the partitioning of the long wave absorption between cloud droplets and water vapor [Davies, 1985]. The value of this radiatively forced equilibrium, together with the effects of convection and entrainment, determines the condensation growth for droplets smaller than $\approx 5 \mu \mathrm{m}$ near cloud top.

Droplets larger than $10 \mu \mathrm{m}$ can grow even under very low supersaturations through direct cooling to space. The details of this radiatively driven droplet growth may be particularly important in 200- to 400-m-thick layer clouds. Given droplet concentrations between 50 and $150 \mathrm{~cm}^{-3}$, condensation growth produces 10-14 $\mu \mathrm{m}$ mean droplet radii near cloud top, with maximum liquid water mixing ratios of $\mathrm{w}_{1} \approx 0.4-0.8 \mathrm{~g} \mathrm{~kg}^{-1}$. Autoconversion rates (the rate of formation of embryonic precipitation particles) given these distribution parameters are several orders of magnitude below those typical of deeper cumuli with larger liquid water contents [Austin et al., 1995], but both observations [Nicholls, 1984; Austin et al., 1995] and models [Nicholls, 1987; Baker, 1993; Austin et al., 1995] indicate that signif- 
icant precipitation can be produced by these clouds. One factor that can accelerate precipitation development for shallow clouds is the condensation growth of cloud droplets in updrafts [Kovetz and Olund, 1969; Jonas and Mason, 1974]; radiative cooling at cloud top might be expected to have a similar impact on accelerating the onset of precipitation in layer clouds.

Below we will use model-derived radiative profiles from typical marine stratocumulus clouds to study the condensation growth of radiatively-cooled cloud droplets, the evolution of the equilibrium supersaturation, and the initiation of precipitation. The cloud droplet radiative environment will be specified using the model of Siems et al. [1993] (referred to below as SLB); it gives profiles of temperature, vapor mixing ratio, and the upward and downward long wave fluxes for a nocturnal cloud in which a subsiding layer of overlying air determines the radiative balance at cloud top.

In Section 2 we derive an expression for the equilibrium supersaturation, $S_{\text {eq }}$, and calculate an upper bound on $\mathrm{S}_{\mathrm{eq}}$ for typical cloud radiative and microphysical conditions. We use the SLB model to obtain vertical profiles of the total net emission (termed the "radiative exchange" by Roach [1976]) and the fraction of the total cooling due to cloud droplets and model droplet condensation growth given this radiative environment. In Section 3 we calculate droplet coalescence near cloud top and compare it to coalescence in updrafts typical of nocturnal stratocumulus clouds. Section 4 contains a discussion of these results.

\section{Condensation Growth and the Equilibrium Supersaturation}

\subsection{Radiative Fluxes: The Two Stream Approx- imation}

We will calculate radiative cooling due to absorption and emission by cloud droplets, water vapor, and carbon dioxide using the five-band model of Roach and Slingo [1979]. The wavelength ranges for the five bands are given by Table 1; the model includes parameterizations for the transmissivity of water vapor, carbon dioxide, and cloud droplets and can be run at arbitrary vertical resolution. Given model values for $\mathrm{E}_{\mathrm{i}}^{+}$and $\mathrm{E}_{\mathrm{i}}^{-}$ we can write the net flux divergence in band $i$ as the sum of separate contributions from the droplets and gas [Bott et al., 1990]:

Table 1. Band Wavelength Ranges for Roach and Slingo [1979]

\begin{tabular}{clr}
\hline band & wavenumber $\left(\mathrm{cm}^{-1}\right)$ & $\lambda(\mu \mathrm{m})$ \\
\hline 1 & $0-400$ & $25-\infty$ \\
2 & $400-560$ & $17.9-25$ \\
3 & $560-800$ & $12.5-17.9$ \\
4 & $800-1150$ & $8.7-12.5$ \\
5 & $1150-2050$ & $4.9-8.7$ \\
\hline
\end{tabular}

$$
\begin{aligned}
\left(\frac{\mathrm{dE}_{\mathrm{n}, \mathrm{i}}}{\mathrm{dz}}\right) & \approx\left(\kappa_{\mathrm{drops}, \mathrm{i}}+\kappa_{\mathrm{gas}, \mathrm{i}}\right) 4\left(\mathrm{~B}_{\mathrm{i}}-0.5\left(\mathrm{E}_{\mathrm{i}}^{+}+\mathrm{E}_{\mathrm{i}}^{-}\right)\right) \\
& =\left(\kappa_{\mathrm{drops}, \mathrm{i}}+\kappa_{\mathrm{gas}, \mathrm{i}}\right) 4 \mathrm{E}_{\mathrm{d}, \mathrm{i}} \\
& =\left(\frac{\mathrm{dE}, \mathrm{i}}{\mathrm{dz}}\right)_{\mathrm{drops}}+\left(\frac{\mathrm{E}_{\mathrm{n}, \mathrm{i}}}{\mathrm{dz}}\right)_{\mathrm{gas}}
\end{aligned}
$$

where $\kappa_{\mathrm{drops}, \mathrm{i}}$ and $\kappa_{\mathrm{gas}, \mathrm{i}}\left(\mathrm{m}^{-1}\right)$ are the absorption coefficients in band $i ; B_{i}, E_{i}^{+}$, and $E_{i}^{-}\left(W^{-2}\right)$ are the Planck function and the upward and downward irradiances; the subscript $\mathbf{n}$ denotes the net upward flux $\mathrm{E}_{\mathrm{i}}^{+}-\mathrm{E}_{\mathrm{i}}^{-} ;$and $\mathrm{z}$ is the height (see the Notation list for a full list of symbols).

The thermal emission and the upward and downward irradiances combine to give the radiative exchange defined by Roach [1976] as the net power leaving a droplet of radius $r$ per unit area per unit absorption efficiency:

$$
\mathrm{E}_{\mathrm{d}, \mathrm{i}}=\left(\mathrm{B}_{\mathrm{i}}-0.5\left(\mathrm{E}_{\mathrm{i}}^{+}+\mathrm{E}_{\mathrm{i}}^{-}\right)\right)
$$

Given $\mathrm{n}(\mathrm{r}) \mathrm{dr}\left(\mathrm{kg}^{-1}\right)$, the mixing ratio of droplets with radii between $r$ and $r+d r$, and $Q_{a}(r, i)$, the absorption efficiency for droplets in spectral band $i$, we can write that portion of the flux divergence due to droplets in terms of $F_{d}(r, i)(W)$, the net power radiating from a droplet of radius $r$ in spectral interval i:

$$
\begin{aligned}
\left(\frac{\mathrm{dE}_{\mathrm{n}, \mathrm{i}}}{\mathrm{dz}}\right)_{\mathrm{drops}} & =\rho_{\mathrm{a}} \int_{0}^{\infty} \mathrm{n}(\mathrm{r}) \pi \mathrm{r}^{2} \mathrm{Q}_{\mathrm{a}}(\mathrm{r}, \mathrm{i}) 4 \mathrm{E}_{\mathrm{d}, \mathrm{i}} \mathrm{dr} \\
& =\rho_{\mathrm{a}} \int_{0}^{\infty} \mathrm{n}(\mathrm{r}) \mathrm{F}_{\mathrm{d}, \mathrm{i}}(\mathrm{r}) \mathrm{dr}
\end{aligned}
$$

where $\rho_{\mathrm{a}}$ is the density of dry air.

\subsection{Droplet Growth Equations}

We can calculate droplet growth given $E_{d, i}$, the size and composition of the cloud condensation nucleus, and the thermodynamic state variables. The droplet growth equation including radiation is [Roach, 1976]

$$
\mathrm{r} \frac{\mathrm{dr}}{\mathrm{dt}}=\mathrm{G}(\mathrm{r})\left(\mathrm{S}-\mathrm{C}_{\mathrm{K}}+\mathrm{C}_{\mathrm{R}}+\frac{\mathrm{L}_{\mathrm{v}} \mathrm{F}_{\mathrm{d}}}{4 \pi \mathrm{r} \mathrm{K}^{\prime} \mathrm{R}_{\mathrm{v}} \mathrm{T}^{2}}\right)
$$

where $r$ is the radius, $S$ is the supersaturation, $t$ is the time, and the Kelvin and Raoult terms $\left(\mathrm{C}_{K}, \mathrm{C}_{\mathrm{R}}\right)$ are given in the Notation list. We have dropped the band subscript $i$ from $F_{d}$ to denote summation over the five bands.

For a closed parcel exposed to net flux divergence the conservation equations for energy and water are

$$
\begin{gathered}
c_{\mathrm{pm}} \frac{\mathrm{dT}}{\mathrm{dt}}=-\mathrm{L}_{\mathrm{v}} \frac{\mathrm{dw}_{\mathrm{v}}}{\mathrm{dt}}+\frac{\mathrm{R}_{\mathrm{d}} \mathrm{T}}{\mathrm{p}} \frac{\mathrm{dp}}{\mathrm{dt}}-\frac{1}{\rho_{\mathrm{a}}} \frac{\mathrm{dE}_{\mathrm{n}}}{\mathrm{dz}} \\
\frac{\mathrm{dw}_{\mathrm{v}}}{\mathrm{dt}}=-\frac{\mathrm{dw_{ \textrm {l } }}}{\mathrm{dt}}=-4 \pi \rho_{\mathrm{l}} \int_{0}^{\infty} \mathrm{n}(\mathrm{r}) \mathrm{r}^{2} \frac{\mathrm{dr}}{\mathrm{dt}} \mathrm{dr}
\end{gathered}
$$

where $w$ is the vertical velocity, $w_{v}$ and $w_{l}$ are the vapor and liquid mixing ratios, and $c_{p m}=c_{p d}+\left(w_{v}+w_{l}\right) c_{w}$ is the heat capacity of the cloudy air. 
Together with the hydrostatic equation, (4)-(6) can be solved given an initial droplet number distribution $\mathrm{n}(\mathrm{r})$. The supersaturation $\mathrm{S}$ can be diagnosed at each time step through the definition

$$
\mathrm{S}=\frac{\mathrm{e}}{\mathrm{e}_{\mathrm{s}}(\mathrm{T})}-1=\frac{\mathrm{p}}{\mathrm{e}_{\mathrm{s}}(\mathrm{T})\left(1+\epsilon / \mathrm{w}_{\mathrm{v}}\right)}-1
$$

If the updraft velocity and/or the flux divergence are steady on timescales longer than a few seconds, it can be shown that the supersaturation calculated by the integration of (4) - (6) relaxes to a quasi-equilibrium value $\mathrm{S}_{\mathrm{eq}}$ [Roach, 1976; Davies, 1985]. We use the approach of Davies [1985] to derive an expression for $\mathrm{S}_{\mathrm{eq}}$ in the Appendix; in a closed parcel it is determined predominately by the vertical velocity, the net flux divergence and the integral radius, $\mathrm{I}$ :

$$
\begin{aligned}
& \mathrm{S}_{\mathrm{eq}} \approx \mathrm{a}_{1} \tau_{\mathrm{s}} \mathrm{w}+\overline{\mathrm{C}_{\mathrm{K}}}-\overline{\mathrm{C}_{\mathrm{r}}} \\
& -\frac{a_{3}}{4 \pi \mathrm{I} \overline{\mathrm{G}}}\left\langle\frac{\mathrm{G}}{\mathrm{K}^{\prime}}\right\rangle\left(\frac{1}{\rho_{\mathrm{a}}} \frac{\mathrm{dE}_{\mathrm{n}}}{\mathrm{dz}}\right)_{\mathrm{drops}} \\
& +\frac{\mathrm{a}_{3}}{4 \pi \rho_{1} \mathrm{a}_{2} \overline{\mathrm{G}} \mathbf{c}_{\mathrm{pm}} \mathrm{I}}\left(\frac{1}{\rho_{\mathrm{a}}} \frac{\mathrm{dE}}{\mathrm{dz}}\right)_{\text {total }}
\end{aligned}
$$

where $I=\int \mathrm{rn}(\mathrm{r}) \mathrm{dr}, \mathrm{a}_{1}, \mathrm{a}_{2}$ and $\mathrm{a}_{3}$ are slowly varying functions of the pressure and temperature and $\tau_{\mathrm{s}}=$ $1 /\left(4 \pi \rho_{1} a_{2} \overline{G I}\right)$ is the relaxation time (see, for example, Cooper [1989]). The overbars in (8) represent an average weighted by the integral radius, while the angle brackets represent an average weighted by the droplet flux divergence (see the Appendix).

We show in the Appendix that for typical stratocumulus droplet and aerosol distributions, $\overline{\mathrm{C}_{\mathrm{r}}}$ is 2 orders of magnitude smaller than $\overline{\mathrm{C}_{\mathbf{k}}}$. With this approximation, and assuming $w=0,(8)$ can be written in a more compact form:

$$
\begin{aligned}
\mathrm{S}_{\mathrm{eq}} & \approx \overline{\mathrm{C}_{\mathrm{K}}} \\
& +\frac{\mathrm{a}_{3}}{4 \pi \mathrm{I}}\left(\frac{1}{\rho_{\mathrm{a}}} \frac{\mathrm{dE}_{\mathrm{n}}}{\mathrm{dz}}\right)_{\text {total }}\left[\frac{1}{\rho_{1} \mathrm{a}_{2} \overline{\mathrm{G}} \mathrm{c}_{\mathrm{pm}}}-\frac{\mathrm{F}}{\overline{\mathrm{K}^{\prime}}}\right]
\end{aligned}
$$

where $F=\left(\mathrm{dE}_{\mathrm{n}} / \mathrm{dz}\right)_{\text {drops }} /\left(\mathrm{dE}_{\mathrm{n}} / \mathrm{dz}\right)_{\text {total }}$ is the fraction of the total flux divergence due to the droplets [Davies, 1985]. We will follow Fukuta and Walter [1970] and use $\alpha=1, \beta=0.04$ in (8)-(10), which produces $\mathrm{a}_{\alpha} \approx 0.1 \mu \mathrm{m}, \mathrm{a}_{\beta} \approx 4 \mu \mathrm{m}$. As a result, $\mathrm{K}^{\prime}$ is not a strong function of droplet radius, while $\mathrm{G}$ increases with increasing droplet size.

\subsection{Radiative Fluxes: Cloud Flux Profiles}

The radiative exchange $E_{d, i}$ at cloud top and the fractional absorption $\mathrm{F}$ due to droplets depend on the magnitude of the downwelling flux from the inversion, the cloud temperature, and the droplet size distribution. We will estimate these using the SLB model, which attempts to establish the interaction between the cloudcapped boundary layer and the overlying air. In this section we will fix the cloud layer thickness at $300 \mathrm{~m}$ and let the subsiding inversion evolve to steady state above the cloud for dry (inversion $w_{v}=1 \mathrm{~g} \mathrm{~kg}^{-1}$ ) and moist $\left(w_{v}=5 \mathrm{~g} \mathrm{~kg}^{-1}\right)$ conditions. Adiabatic clouds of this thickness have large cloud top flux divergences beneath a dry inversion and produce a broad range of precipitation rates, apparently modulated by the character of the small droplet population. For example, aircraft measurements during the First International Satellite Cloud Climatology Project (ISCCP) Regional Experiment (FIRE) show no drizzle formation in a 275to 300-m-thick layer with a droplet number concentration of $150 \mathrm{~cm}^{-3}$, while in adjacent clean air, peak rain rates of 5-8 $\mathrm{mm} \mathrm{day}^{-1}$ were observed in a layer of the same thickness but with droplet concentrations below $50 \mathrm{~cm}^{-3}$ [Austin et al., 1995].

We initialize inversion air at a fixed temperature and vapor mixing ratio at a height of $3 \mathrm{~km}$ and let it descend with velocity $\mathrm{Dz}$, where $\mathrm{z}$ is the height of the parcel and $\mathrm{D}$, the large-scale divergence, is set at a fixed value $\mathrm{D}=4 \times 10^{-6} \mathrm{~s}^{-1}$ (a value typical of the large-scale divergence off of the California coast in July). The inversion air warms adiabatically and emits and absorbs long wave radiation as it descends; the inversion temperature above cloud top is controlled through the water vapor mixing ratio, which determines the emissivity, and the subsidence, which determines the time available for the parcel to experience diabatic heating or cooling as it descends. Radiative fluxes are computed at each time step using the Roach and Slingo [1979] model. The model requires several hours to evolve until the overlying, subsiding air is in a quasi-steady state. Following this, the radiative flux divergence changes very slowly; for our purposes, we consider this the steady state radiative flux profile.

Figures 1a and $1 \mathrm{~b}$ show vertical profiles of water vapor mixing ratio, temperature, and liquid water mixing ratio for the 300-m-thick cloud layer and an inversion in which $\mathrm{w}_{\mathrm{v}}=1 \mathrm{~g} \mathrm{~kg}^{-1}$. The total number concentration is constant at $\mathrm{N}_{\mathrm{T}}=50 \mathrm{mg}^{-1}$, and the adiabatic increase of liquid water with height produces a maximum volume mean radius at cloud top of $r_{v o l}=13.4 \mu \mathrm{m}$, where $r_{v o l}$ is defined by

$$
\mathrm{r}_{\mathrm{vol}}=\left(\frac{3 \mathrm{w}_{\mathrm{l}}}{4 \pi \rho_{\mathrm{l}} \mathrm{N}_{\mathrm{T}}}\right)^{1 / 3}
$$

The fluxes for these thermodynamic profiles are calculated on a grid with variable vertical spacing: $\Delta z=$ $2.5 \mathrm{~m}$ in the $10 \mathrm{~m}$ below the inversion, followed by two layers with $5-\mathrm{m}$ spacing, 2 with $10-\mathrm{m}$ spacing, and the remainder set to $\Delta \mathrm{z}=20 \mathrm{~m}$.

Figure 1c shows the corresponding values of the upward and downward irradiances and the total radiative exchange, $\mathrm{E}_{\mathrm{d}}$, summed over the five bands. The warm, dry inversion produces a total downward flux of $\approx 280 \mathrm{~W} \mathrm{~m}^{-2}$, while the upward flux at cloud top is $\approx 320 \mathrm{~W} \mathrm{~m}^{-2}$; droplets in this cloud experience values 

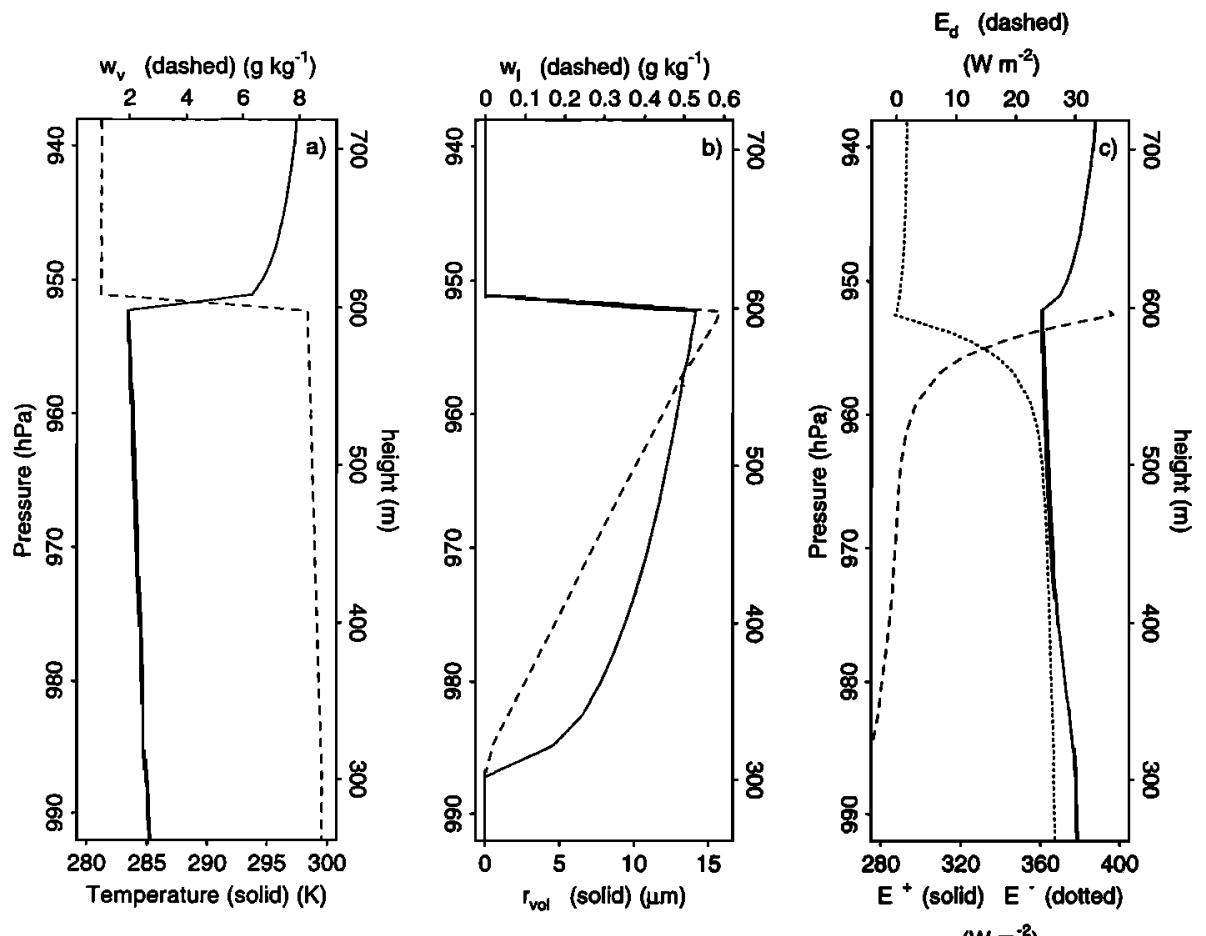

Figure 1. Vertical soundings for a 300-m-thick layer cloud beneath a quasi-steady state inversion (inversion $w_{v}=1 \mathrm{~g} \mathrm{~kg}^{-1}$ ). (a) temperature $\mathrm{T}$ and vapor mixing ratio $\mathrm{w}_{\mathrm{v}} ;$ (b) volume mean radius $r_{\text {vol }}$ (with total number concentration $N_{T}=50 \mathrm{mg}^{-1}$ ) and adiabatic liquid water mixing ratio $\mathrm{w}_{\mathrm{l}}$; (c) total upward and downward irradiances $\mathrm{E}^{+}$and $\mathrm{E}^{-}$and the total radiative exchange $\mathrm{E}_{\mathrm{d}}$

of the radiative exchange varying from 2 to $35 \mathrm{~W} \mathrm{~m}^{-2}$ through the upper $80 \mathrm{~m}$ of the cloud layer. The net flux divergence $\mathrm{dE}_{\mathrm{n}} / \mathrm{dz}$ (not shown) varies from 0.1 to $2.6 \mathrm{~W} \mathrm{~m}^{-3}$ over the same $80-\mathrm{m}$ scale.

Increasing the emissivity of the overlying air significantly reduces both the flux divergence and the radiative exchange. This is shown in Figure 2a, which gives the quasi-steady state radiative profiles for a subsiding inversion with $\mathrm{w}_{\mathrm{v}}=5 \mathrm{~g} \mathrm{~kg}^{-1}$ atop the mixed layer of Figure 1. The peak value of the radiative exchange is reduced by roughly $50 \%$ for this cloud, to $18 \mathrm{~W} \mathrm{~m}^{-2}$ at cloud top, while the maximum net flux divergence is now $1.6 \mathrm{~W} \mathrm{~m}^{-3}$ at cloud top (not shown).

Figure $2 \mathrm{~b}$ shows the impact of droplet removal on the radiative exchange. The liquid water content has been reduced by $50 \%$ at each cloud level by removing droplets, consistent with, for instance, precipitation scavenging. The lower cloud emissivity reduces the downwelling irradiance and increases the radiative exchange near cloud top; $\mathrm{E}_{\mathrm{d}}$ remains above $5 \mathrm{~W} \mathrm{~m}^{-2}$ through the upper $100 \mathrm{~m}$ of the cloud. The $50 \%$ reduction in cloud water also halves the flux divergence through (3), with a new cloud top flux divergence of 1.3 $\mathrm{W} \mathrm{m}^{-3}$.

In Figure 2c, the fraction of the cooling due to droplet emission $\mathrm{F}$ is shown for the adiabatic layer of Figure 1c and the subadiabatic layer of Figure $2 b$. It is estimated using (1):

$$
\mathbf{F}=\frac{\left(\frac{d E_{\mathrm{n}}}{\mathrm{dz}}\right)_{\mathrm{drops}}}{\left(\frac{\mathrm{d} E_{\mathrm{n}}}{\mathrm{dz}}\right)_{\text {total }}} \approx \frac{\kappa_{\mathrm{drops}}}{\kappa_{\mathrm{drops}}+\kappa_{\mathrm{gas}}}
$$

For the subadiabatic and adiabatic clouds the droplets account, respectively, for approximately $80 \%$ and $87 \%$ of the net flux divergence; these relative contributions change little through the upper $100 \mathrm{~m}$ of the cloud.

\subsection{Constraints on $S_{e q}$}

At fixed temperature and pressure, we expect $S_{\text {eq }}$ to be maximum in (10) for large flux divergences and small values of $F, \bar{G}$, and $I$. Table 2 lists values of $\bar{G}$ and $I$ for a range of drop size distributions specified by the modified gamma function of Berry and Reinhardt [1974a]:

$$
\begin{aligned}
\mathrm{n}\left(\mathrm{r}_{\mathrm{j}}\right) & = \\
& \mathrm{N}_{\mathrm{T}} \frac{(1+\nu)^{(1+\nu)}}{\mathrm{r}_{\mathrm{vol}}^{3} \Gamma(\nu+1)}\left(\frac{\mathrm{r}_{\mathrm{j}}^{3}}{\mathrm{r}_{\mathrm{vol}}^{3}}\right)^{\nu} \exp \left[-(1+\nu) \frac{\mathrm{r}_{\mathrm{j}}^{3}}{\mathrm{r}_{\mathrm{vol}}^{3}}\right]
\end{aligned}
$$

where $r_{j}$ is the radius of size class $j, N_{T}$ is the total number mixing ratio, $r_{v o l}$ is the volume mean radius, and $\nu$ is a parameter related to the dispersion of the number distribution. Table 2 also lists two other measures of the distribution moments, $r_{g}$ and $r_{b}$, which will be discussed in Section 3.

Observations from the FIRE indicate that the droplet spectrum below $23 \mu \mathrm{m}$ radius can be fit to distribu- 

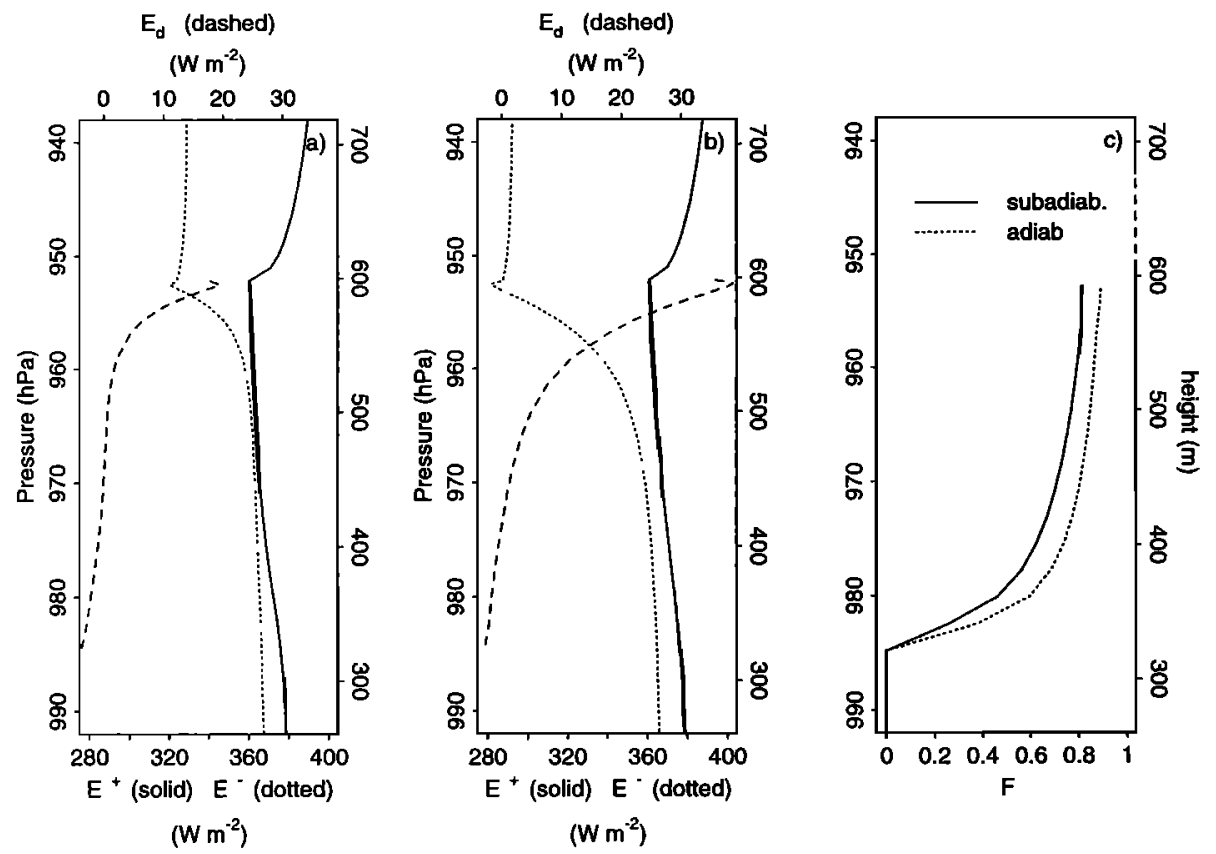

Figure 2. (a) As in Figure 1c but for a moist inversion $\left(w_{v}=5 \mathrm{~g} \mathrm{~kg}^{-1}\right)$. (b) As in Figure 1c but for a cloud with $\mathrm{a} \mathrm{w}_{1}$ profile that is $50 \%$ of adiabatic. (c) Fraction $\mathbf{F}$ of the net flux divergence due to droplet cooling.

tions of the form of (13) with values of $\nu$ ranging from $0.2 \leq \nu \leq 2.2$ [Austin et al., 1995]. The parameter $\nu$ is related to the dispersion $\left(\sigma_{\mathrm{r}} / \overline{\mathbf{r}}\right)$ where $\sigma_{\mathrm{r}}$ is the standard deviation of $n(r)$ and $\bar{r}$ is the mean radius by

$$
\frac{\sigma_{\mathrm{r}}}{\overline{\mathrm{r}}} \approx\left(\frac{1}{7.14(1+\nu)}\right)^{1 / 2}
$$

Thus $0.2 \leq \nu \leq 2.2$ is equivalent to $0.2 \leq \sigma_{\mathrm{r}} / \overline{\mathrm{r}} \leq 0.35$, in approximate agreement with dispersion values found in North Atlantic stratocumulus by Slingo et al. [1982]. The radiative profiles of Figures 1-2 were computed for distributions of the form of (13) with $\nu=0.3, \mathrm{~N}_{\mathrm{T}}=$ $50 \mathrm{mg}^{-1}$, and 25 droplet size categories with $\mathrm{r}_{\mathbf{j}}$ between $1 \leq \mathrm{r}_{\mathrm{j}} \leq 25 \mu \mathrm{m}$. Substituting the other distributions of Table 2 (while keeping the dry inversion, 300-m cloud thickness, and adiabatic liquid water profile) changes the cloud top cooling rate by less than $20 \%$.
Although I, F, and $\bar{G}$ will vary with local changes in the droplet distribution, other coefficients in (8) remain approximately constant over a broad range of temperatures, pressures, and drop size distributions. The thermodynamic coefficients $a_{1}, a_{2}$, and $a_{3}$ vary by less than $15 \%$ in the temperature and pressure range $273 \mathrm{~K}<\mathrm{T}<293 \mathrm{~K}, 1000 \mathrm{hPa}<\mathrm{p}<800 \mathrm{hPa}$. The microphysical coefficients $\overline{\mathrm{C}_{\mathrm{r}}}, \overline{\mathrm{C}_{\mathrm{k}}}, \overline{\mathrm{K}^{\prime}}$ depend weakly on the drop size distribution, but can be considered constant for the range of distributions given by Table 2 . Table 3 shows values for each of these parameters for a cloud top temperature and pressure of $\mathrm{T}=283.5 \mathrm{~K}$, $\mathrm{p}=954.5 \mathrm{hPa}$.

The equilibrium supersaturation is held within a comparatively narrow range for the coefficient values of Tables 2 and 3 . The second term in (10) remains greater than zero for all values of $\bar{G}$, so that the minimum $S_{\text {eq }}$ is set by $\overline{C_{k}}=10^{-4}$. To compute an upper bound on $S_{\text {eq }}$

Table 2. Gamma Distributions for Fixed $\mathrm{w}_{1}=0.5 \mathrm{~g} \mathrm{~kg}^{-1}$

\begin{tabular}{rrrrrrrrrr}
\hline Case & $\begin{array}{r}\mathbf{r}_{\text {vol }} \\
(\mu \mathrm{m})\end{array}$ & $\begin{array}{r}\mathbf{w}_{1} \\
\left(\mathrm{~g} \mathrm{~kg}^{-1}\right)\end{array}$ & $\begin{array}{r}\mathrm{N}_{\mathrm{T}} \\
\left(\mathrm{mg}^{-1}\right)\end{array}$ & $\nu$ & $\sigma_{\mathrm{r}} / \overline{\mathbf{r}}$ & $\begin{array}{r}\mathbf{r}_{\mathrm{g}} \\
(\mu \mathrm{m})\end{array}$ & $\begin{array}{r}\mathbf{r}_{\mathrm{b}} \\
(\mu \mathrm{m})\end{array}$ & $\begin{array}{r}\mathrm{I} \\
\left(\mathrm{m} \mathrm{kg}^{-1}\right)\end{array}$ & $\begin{array}{r}\mathrm{G} \\
\left(\mu \mathrm{m}^{2} \mathrm{~s}^{-1}\right)\end{array}$ \\
\hline 1 & 10 & 0.5 & 119.36 & 0.45 & 0.31 & 11.91 & 9.40 & 1103.8 & 76.4 \\
2 & 10 & 0.5 & 119.36 & 0.30 & 0.33 & 12.09 & 9.57 & 1093.9 & 76.3 \\
3 & 10 & 0.5 & 119.36 & 0.00 & 0.37 & 12.60 & 10.00 & 1065.9 & 76.1 \\
4 & 11 & 0.5 & 89.68 & 0.45 & 0.31 & 13.10 & 10.34 & 912.2 & 77.5 \\
5 & 11 & 0.5 & 89.68 & 0.30 & 0.33 & 13.30 & 10.53 & 904.1 & 77.4 \\
6 & 11 & 0.5 & 89.68 & 0.00 & 0.37 & 13.86 & 11.00 & 880.9 & 77.2 \\
7 & 12 & 0.5 & 69.08 & 0.45 & 0.31 & 14.29 & 11.28 & 766.6 & 78.4 \\
8 & 12 & 0.5 & 69.08 & 0.30 & 0.33 & 14.51 & 11.49 & 759.7 & 78.3 \\
9 & 12 & 0.5 & 69.08 & 0.00 & 0.37 & 15.48 & 12.00 & 740.2 & 78.1 \\
10 & 14 & 0.5 & 43.50 & 0.45 & 0.31 & 16.67 & 13.16 & 563.2 & 79.9 \\
11 & 16 & 0.5 & 29.14 & 0.45 & 0.31 & 19.06 & 15.03 & 431.1 & 81.0 \\
\hline
\end{tabular}


Table 3. Coefficient Values for (8)

\begin{tabular}{lc}
\hline Coefficient & Value \\
\hline $\mathrm{T}, \mathrm{K}$ & 283.5 \\
$\mathrm{p}, \mathrm{hPa}$ & 954.5 \\
$\mathrm{a}_{1}, \mathrm{~m}^{-1}$ & $5.2 \times 10^{-4}$ \\
$\mathrm{a}_{2}$ & 283.1 \\
$\mathrm{a}_{3}, \mathrm{~J}^{-1} \mathrm{~K} \mathrm{~kg}$ & 0.067 \\
$\rho_{\mathrm{l}}, \mathrm{kg} \mathrm{m}^{-3}$ & 1000 \\
$\overline{\mathrm{C}_{\mathrm{k}}}$ & $1.0 \times 10^{-4}$ \\
$\overline{\mathrm{C}_{\mathrm{r}}}$ & $9.7 \times 10^{-7}$ \\
$\mathrm{c}_{\mathrm{pm}}, \mathrm{J} \mathrm{kg}^{-1} \mathrm{~K}^{-1}$ & 1020 \\
$\overline{\mathrm{K}^{\prime}}, \mathrm{J} \mathrm{m} \mathrm{s} \mathrm{K}^{-1}$ & 0.024 \\
$\rho_{\mathrm{a}}, \mathrm{kg} \mathrm{m}^{-3}$ & 1.17 \\
$\tau_{\mathrm{s}}, \mathrm{s}$ & 4.6 \\
\hline
\end{tabular}

using the conditions suggested by Figures 1 and 2, we take $\mathrm{F}=0.87,\left(\mathrm{dE}_{\mathrm{n}} / \mathrm{dz}\right)_{\text {total }}=10 \mathrm{~K} \mathrm{hr}^{-1}\left(3.3 \mathrm{~W} \mathrm{~m}^{-3}\right)$ and the drop size distribution of Case 11. This yields $\mathrm{S}_{\mathrm{eq}}=3.7 \times 10^{-4}$. The equilibrium supersaturation decreases as $N_{T}$ increases: inserting $(I, \bar{G})$ for Case 1, Table 2 halves the radiative contribution to $S_{\text {eq }}$ and reduces it to $\mathrm{S}_{\text {eq }}=2.2 \times 10^{-4}$. These low $\mathrm{S}_{\mathrm{eq}}$ values preclude any significant radiatively-induced aerosol activation at the tops of the cloud layers presented here; roughly $97 \%$ of the CCN distribution described in the Appendix require supersaturations larger than $0.037 \%$ for activation.

\subsection{Condensation Growth Calculations}

The equilibrium values of the supersaturation for the examples given above are small enough so that in the absence of upward motion, droplets with radii less than $\approx 5 \mu \mathrm{m}$ evaporate throughout much of the upper part of the clouds shown in Figures 1-2. Figure 3 shows the growth histories of 25 droplet classes (solid lines) computed by an explicit integration of (4)-(6) for conditions taken from Figure 1. For this case we locate the drop size distribution $40 \mathrm{~m}$ below cloud top, in a parcel of adiabatic cloud base air that remains at that height as it cools. The value of $E_{d}$ is $7.3 \mathrm{~W} \mathrm{~m}^{-2}$ at this height, while the initial drop size distribution has an adiabatic liquid water content of $0.5 \mathrm{~g} \mathrm{~kg}^{-1}$ and $\mathrm{r}_{\mathrm{vol}}=13.3 \mu \mathrm{m}$. The droplets and vapor produce a combined net flux divergence of $0.93 \mathrm{~W} \mathrm{~m}^{-3}$, with an initial cooling rate (including the effects of phase change) of $-1.6 \mathrm{~K} \mathrm{hr}^{-1}$.

Over the course of 11 minutes in this environment the cooling decreases the parcel temperature by $0.25 \mathrm{~K}$ and lowers the parcel saturation level (the pressure at which the parcel would be exactly saturated) by approximately $10 \mathrm{hPa}$. The solid lines in Figure 3 show the growth histories of individual droplet categories during this time. The critical radius and supersaturation for this aerosol mass are $1.48 \mu \mathrm{m}$ and $5 \times 10^{-4}$, respectively, so that the smallest droplets assume their unactivated equilibrium radii, while droplets smaller than $5 \mu \mathrm{m}$ evaporate until they deactivate. Droplets larger than $10 \mu \mathrm{m}$ grow at between 0.10 and $0.14 \mu \mathrm{m} \mathrm{min}{ }^{-1}$,

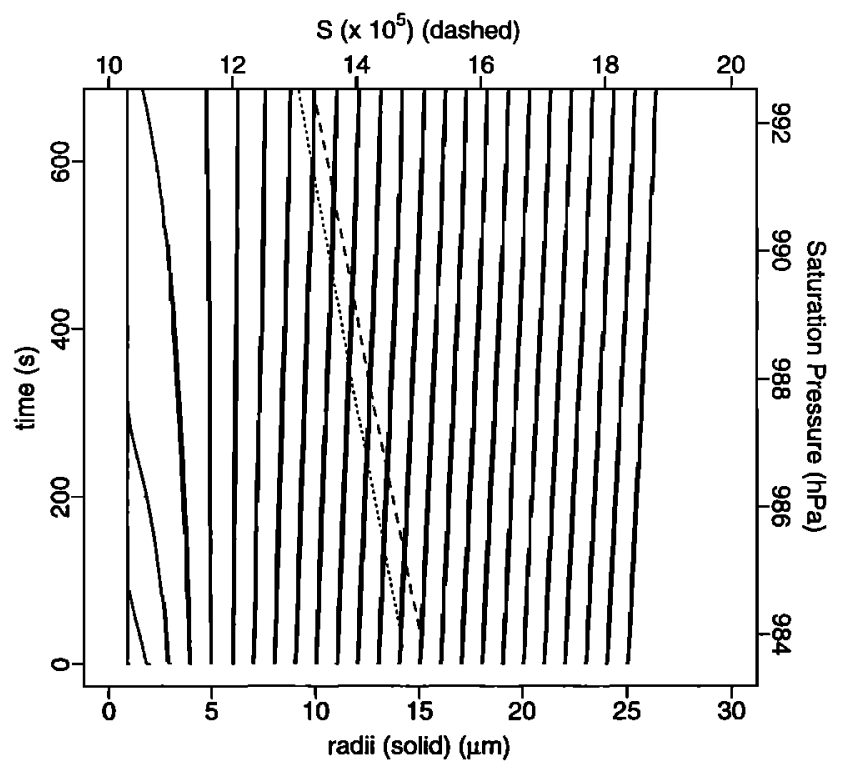

Figure 3. Evolution of an adiabatic drop size distribution $40 \mathrm{~m}$ below cloud top. Solid lines show the droplet radii for size classes 1-25 as a function of time and parcel saturation pressure. The dashed and dotted lines show the equilibrium supersaturation calculated by (8) (dashed line) and (10) (dotted line).

with a growth rate that varies linearly with $E_{d}$ for fixed droplet size.

The supersaturation decreases during the cooling, as larger droplets increase the distribution mean radius (and therefore increase I) by $1.1 \mu \mathrm{m}$ from $12.2 \mu \mathrm{m}$ to $13.3 \mu \mathrm{m}$. The flux divergence decreases by $\approx 4 \%$ over this time period (not shown), as reduced thermal emission is offset by an increase in the droplet absorption coefficient $\kappa_{\text {drops. }}$. The dashed line on Figure 3 shows $\mathrm{S}_{\mathrm{eq}}$ given by (8); it differs from the actual supersaturation by less than $0.1 \%$ over the course of the integration. Also shown is the approximate value given by (10), which is within $2 \%$ of the more accurate value.

Figure 4 shows the contribution of individual terms in the droplet growth equation (4) to the growth rate at the beginning of the integration. Both the supersaturation term ("S") and the radiative cooling term $\left(C_{E}=L_{v} F_{d} /\left(4 \pi r K^{\prime} R_{v} T^{2}\right)\right)$ contribute to the growth of 5 - $\mu \mathrm{m}$ cloud droplets, while the aerosol mass (term $\mathrm{R}$ ) has little impact on the threshold size at which drops begin to evaporate. Droplets smaller than $3 \mu \mathrm{m}$ will not evaporate provided $\mathrm{S}_{\mathrm{eq}}>0.03 \%$, which would be produced by a radiative exchange greater than $\approx 25 \mathrm{~W} \mathrm{~m}^{-2}$ for this drop size distribution. From Table 3 and (8), $\mathrm{S}_{\text {eq }}>0.03 \%$ would also be produced by updrafts at cloud top larger than $\approx 0.1 \mathrm{~m} \mathrm{~s}^{-1}$.

\section{Coalescence With Radiative Cooling}

As the value of the radiative exchange increases beyond $10 \mathrm{~W} \mathrm{~m}^{-2}$, the radiatively driven growth rates of 


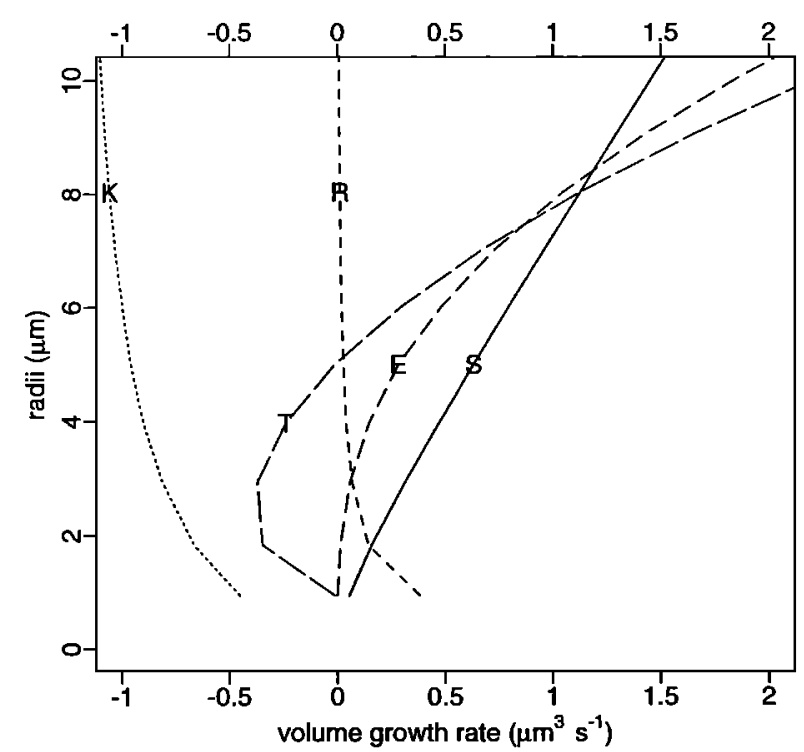

Figure 4. Volume growth rate $4 \pi r^{2} \mathrm{dr} / \mathrm{dt}$ as a function of radius for a radiative exchange $\mathrm{E}_{\mathrm{d}}=7.5 \mathrm{~W} \mathrm{~m}^{-2}$ and an equilibrium supersaturation of $1.5 \times 10^{-4}$. The symbols designate the terms from (4): $S=S, K=C_{K}$, $\mathrm{R}=\mathrm{C}_{\mathrm{R}}, \mathrm{E}=$ cooling term, $\mathrm{T}=\mathrm{S}+\mathrm{K}+\mathrm{R}+\mathrm{E}$

the larger droplets exceed those produced by typical updrafts in stratocumulus clouds. Figure 5 shows the individual terms of (4) (given a total radiative exchange of $\mathrm{E}_{\mathrm{d}}=17.5 \mathrm{~W} \mathrm{~m}^{-2}$ ) compared with the supersaturation term assuming $\mathrm{S}=10^{-3}$ (generated, for instance, by a $0.35 \mathrm{~m} \mathrm{~s}^{-1}$ updraft acting on the initial drop size distribution of Figure 3). Radiation has a substantial impact on the growth of the larger droplets; it is the droplets in the $20-25 \mu \mathrm{m}$ size range that determine the initial coalescence growth rate of the condensation-produced droplet size distribution. Coalescence is particularly

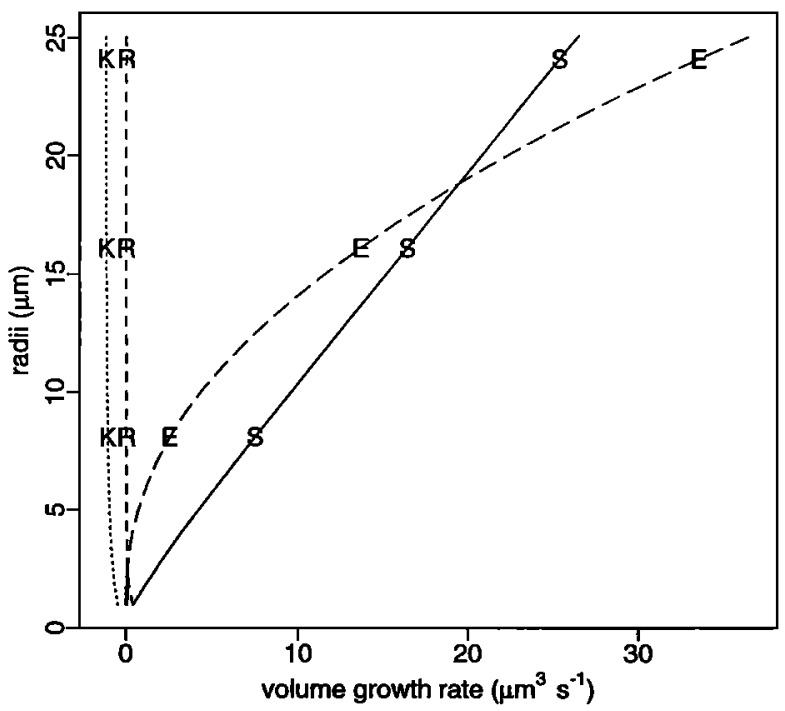

Figure 5. As in Figure 4 but for $E_{d}=17.5 \mathrm{~W} \mathrm{~m}^{-2}$. Line " $S$ " shows the growth rate due to a supersaturation of $\mathrm{S}=1 . \times 10^{-3}$ for comparison. sensitive to size increases in these droplet categories, because the collision efficiency increases from 0.02 to 0.2 as droplets grow through this $5-\mu \mathrm{m}$ radius range [Jonas, 1972]. Even modest condensation growth can have a rate-determining impact on the early stages of coalescence if it accelerates this droplet growth.

In this section we will calculate coalescence growth for a sedimenting droplet population in a region of constant radiative exchange and in an updraft with a constant vertical velocity. Berry and Reinhardt $[1974 \mathrm{~b}]$ showed that a representative measure of the progress of coalescence in an evolving droplet population is given by the mass mean, or "predominant" radius, $r_{g}$. This is defined by

$$
\begin{aligned}
& x_{\mathrm{g}}=\int \mathrm{x}^{2} \mathrm{n}(\mathrm{x}) \mathrm{dx} / \int \mathrm{xn}(\mathrm{x}) \mathrm{dx} \\
& \mathrm{r}_{\mathrm{g}}=\left(\frac{3}{4 \pi \rho_{1}}\right)^{(1 / 3)}\left(\mathrm{x}_{\mathrm{g}}\right)^{(1 / 3)}
\end{aligned}
$$

where $\mathrm{x}$ is the droplet mass. Values of $\mathrm{r}_{\mathrm{g}}$ for precipitating stratocumulus observed during FIRE range from $45<\mathrm{r}_{\mathrm{g}}<75 \mu \mathrm{m}$ for midcloud rain rates of $1-10$ mm day ${ }^{-1}$.

We will use $T_{g}$, the time required for $\mathbf{r}_{g}$ to grow to $50 \mu \mathrm{m}$, as a measure of the rate of spectral evolution of an initial drop size distribution. Berry and Reinhardt [1974b] found that for a coalescing droplet population (without cooling or supersaturation growth), $1 / \mathrm{T}_{\mathrm{g}}$ was linearly related to the liquid water content of the initial distribution and to $r_{b}$, a measure of the initial normalized mass variance:

$$
\begin{aligned}
\operatorname{nvar} x & =\frac{\left(\left\langle\mathrm{x}^{2}\right\rangle-\langle\mathrm{x}\rangle^{2}\right)}{\langle\mathrm{x}\rangle^{2}}=1 /(1+\nu) \\
\mathrm{r}_{\mathrm{b}}^{3} & =\mathrm{r}_{\mathrm{vol}}^{3} \operatorname{nvar}^{1 / 2} \mathrm{x}=\mathrm{r}_{\mathrm{vol}}^{3} \sqrt{\frac{1}{1+\nu}}
\end{aligned}
$$

where the angle brackets define an average over the mass distribution.

We calculate the evolution of $r_{g}$ for the initial distributions of Table 2, integrating the stochastic collection equation using the algorithm and the kernel of Berry and Reinhardt [1974a] (with collection efficiencies taken from Hocking and Jonas [1970] and Shafrir and Neiburger [1963]). Coalescence growth is calculated using 60 logarithmically spaced radius bins between 2 and $1800 \mu \mathrm{m}$ radius, and for each 2 -s time step we also compute condensation growth using the advection equation:

$$
\left(\frac{\partial \mathrm{n}(\mathrm{r}, \mathrm{t})}{\partial \mathrm{t}}\right)_{\text {cond }}=-\frac{\partial}{\partial \mathrm{r}}\left[\frac{\mathrm{dr}}{\mathrm{dt}} \mathrm{n}(\mathrm{r}, \mathrm{t})\right]
$$

We solve (17) using the semi-Lagrangian advection scheme of Bott et al. [1990] and the droplet growth equation (4) with $S=C_{K}=C_{R}=0$ (for the cooling cases), and $S=S_{e q}, C_{K}=C_{R}=C_{E}=0$ (for the 
updraft cases). The pressure and temperature are fixed to their values in Table 3. For this calculation we make the approximation that

$$
\mathrm{F}_{\mathrm{d}}=\pi \mathrm{r}^{2} \sum_{\mathrm{i}=1}^{5} \mathrm{Q}_{\mathrm{a}}(\mathrm{r}, \mathrm{i}) 4 \mathrm{E}_{\mathrm{d}, \mathrm{i}} \approx \pi \mathrm{r}^{2} \overline{\mathrm{Q}_{\mathrm{a}}}(\mathrm{r}) 4 \mathrm{E}_{\mathrm{d}}
$$

where the average absorption efficiency, $\overline{Q_{\mathbf{a}}}$ is taken from Roach [1976]:

$$
\overline{\mathrm{Q}_{\mathrm{a}}}=1.18(1-\exp (-0.28 \mathrm{r}))
$$

with $\mathbf{r}$ given in microns. Although this approximation overestimates $F_{d}$ by $5-30 \%$ for droplets with radii between 5 and $15 \mu \mathrm{m}$, the errors decrease with increasing drop size, and are below $4 \%$ for drops larger than 20 $\mu \mathrm{m}$.

Figure 6 shows the time evolution of $r_{g}$ for four different values of the radiative exchange $\mathrm{E}_{d}(3.75,7.5$, $15,25) \mathrm{W} \mathrm{m}^{-2}$ and three different initial drop size distributions (Cases 1, 4, and 7 in Table 2). Also shown for Case 1 is the evolution with neither cooling or vertical ascent (" $\mathrm{n}$ ") and with a constant vertical velocity of $\mathrm{w}=0.5 \mathrm{~m} \mathrm{~s}^{-1}$ (initial $\mathrm{S}_{\mathrm{eq}}=\mathrm{a}_{1} \tau_{\mathrm{s}} \mathrm{w}=8.3 \times 10^{-4}$ ).

Figure 6 shows that coalescence without cooling or ascent (line " $n$ ") proceeds very slowly for this kernel, with the predominant radius $r_{\mathrm{g}}$ growing at roughly $6 \times 10^{-3} \mu \mathrm{m} \mathrm{min}^{-1}$. Placing the parcel in a steady 0.5 $\mathrm{m} \mathrm{s}^{-1}$ updraft (line " $\mathrm{w}$ ") increases this growth rate by

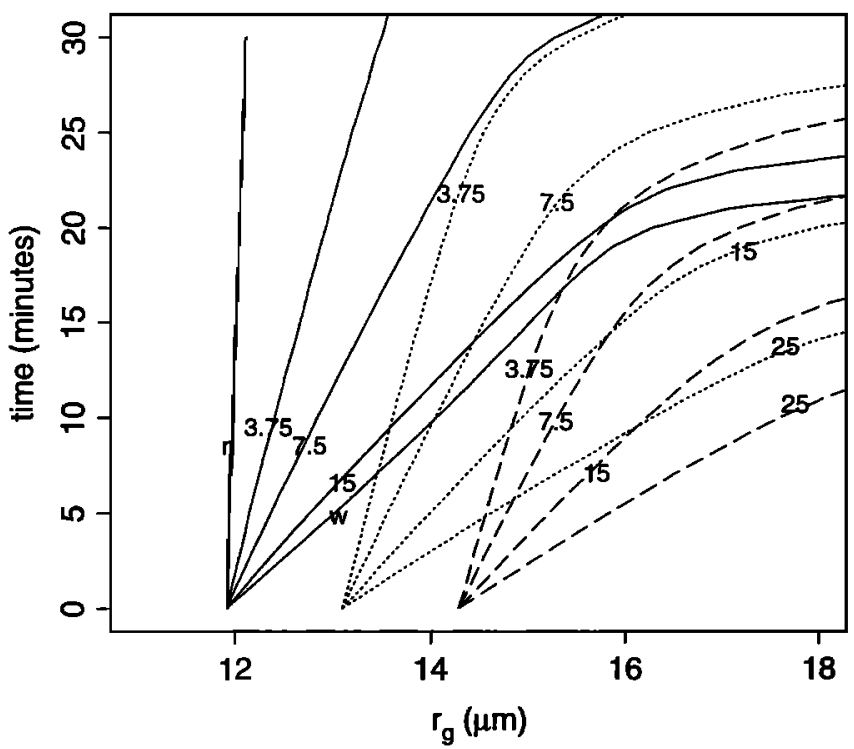

Figure 6. Stochastic coalescence with radiative cooling: predominant $r_{g}$ versus time for three different drop size distributions (Cases 1, 4, and 7) and four values of the radiative exchange $E_{d}=3.75,7.5,15,25 \mathrm{~W} \mathrm{~m}^{-2}$. Solid lines are $r_{\mathrm{vol}}=10 \mu \mathrm{m}$. Dotted lines are $r_{\mathrm{vol}}=$ $11 \mu \mathrm{m}$. Dashed lines are $\mathrm{r}_{\mathrm{vol}}=12 \mu \mathrm{m}$. Also shown are growth curves with neither adiabatic ascent or radiative cooling (" $n$ ") and in a constant updraft of $w=0.5 \mathrm{~m} \mathrm{~s}^{-1}$ ("w") without radiation. a factor of 21. The initial growth rate of the predominant radius is independent of $r_{g}$ and proportional to the radiative exchange, varying for each distribution from $0.05 \mu \mathrm{m} \mathrm{min}^{-1}$ for a radiative exchange of $3.75 \mathrm{~W} \mathrm{~m}^{-2}$ to $0.3 \mu \mathrm{m} \mathrm{min}^{-1}$ for $\mathrm{E}_{\mathrm{d}}=25 \mathrm{~W} \mathrm{~m}^{-2}$. For the smaller $r_{v o l}$ distributions at values of $E_{d}$ less than $15 \mathrm{~W} \mathrm{~m}^{-2}$, there is a transition for $14<r_{g}<16 \mu \mathrm{m}$, in which the growth rate increases by up to an order of magnitude. This change is due to rapidly increasing collection by droplets with radii greater than $30 \mu \mathrm{m}$ (and collection efficiencies approaching unity).

In Figure 7 we plot $r_{g}$ versus $1 / T_{g}$ for four radiative exchanges and three values of the updraft velocity, with the initial distributions of Table 2. The rate of spectral evolution varies linearly with the value of the radiative exchange for these initial distributions. The $\mathrm{w}=0$ curve gives a baseline against which the impact of cooling and ascent can be compared: a radiative exchange of $15 \mathrm{~W} \mathrm{~m}^{-2}$ or an updraft of $0.5 \mathrm{~m} \mathrm{~s}^{-1}$ produces rates of precipitation development (given $r_{v o l}=10 \mu \mathrm{m}$ ) equivalent to those found in a quiescent cloud with a distribution $\mathrm{r}_{\mathrm{vol}} \approx 15 \mu \mathrm{m}$. The time required for the distribution to evolve to $\mathrm{r}_{\mathrm{g}}=50 \mu \mathrm{m}$ decreases from $81 \mathrm{~min}$ for Case 1 (no cooling) to 20.7 min with $E_{d}=25 \mathrm{~W} \mathrm{~m}^{-2}$.

Comparison of the slopes of the curve families in Figure 7 shows different sensitivities to the initial distributions for coalescence aided by supersaturation or radiative cooling. radiatively driven droplet growth is independent of droplet radius once $Q_{a}(r)$ reaches its asymptotic limit (at $\mathrm{r}>15 \mu \mathrm{m}$ ). In contrast, saturationdriven growth for $20 \mu \mathrm{m}$ droplets in an updraft decreases as the droplets grow, because of the $1 / \mathrm{r}$ depen-

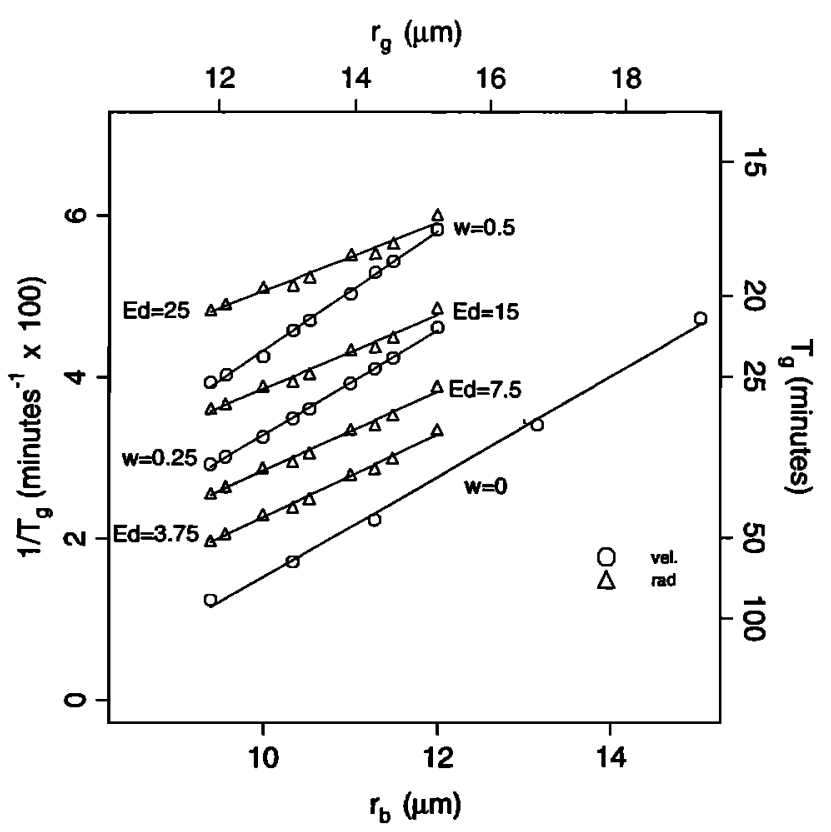

Figure 7. Time $T_{g}$ required to reach $\mathrm{r}_{g}=50 \mu \mathrm{m}$ for the initial distributions of Table 2. Lines are least square fits through the cases, labeled by the appropriate value of the total radiative exchange $E_{d}$ or updraft velocity $w$. 
dence in (4) and because of the decrease in $\mathrm{S}_{\mathrm{eq}}$ as the integral radius increases in (8).

\section{Discussion}

We have modeled radiatively driven droplet growth near cloud top for a 300-m-thick stratocumulus cloud beneath moist and dry inversions. Our results indicate an upper bound on the radiatively-induced supersaturation of less than $0.04 \%$. Equation (10) suggests that this maximum might increase in thicker clouds with a larger total flux divergence, in clouds with lower values of $\mathrm{I}$, or in layers in which vapor absorption constituted a larger fraction of the total layer absorption. Countering such an increase is the coupling of the integral radius and the flux divergence through (3); in the absence of precipitation, an increase in $\mathrm{dE}_{\mathrm{n}} / \mathrm{dz}$ due to increased cloud liquid water content (and the resulting increase in $\kappa_{\text {drops }}$ ) will be offset in (10) by the corresponding increase in $\mathrm{I}$.

If precipitation is considered, observations suggest a second limit, as clean marine clouds with low total droplet concentrations produce drizzle, which removes liquid water and reduces the emissivity (and flux divergence) of the cloud. Measurements from FIRE suggest precipitation scavenging sufficient to halve the cloud liquid water path in less than $25 \mathrm{~min}$ in 250 - to 300 m-thick clouds with $\mathrm{I} \approx 650 \mathrm{~m} \mathrm{~kg}^{-1}\left(\mathrm{~N}_{\mathrm{T}}=50 \mathrm{mg}^{-1}\right.$, $\mathrm{r}_{\mathrm{vol}}=13 \mu \mathrm{m}$ ) [Austin et al., 1995]. This leaves a reduction in $\mathrm{F}$ as the third possibility for increased values of $\mathrm{S}_{\mathrm{eq}}$, but the results of Section 2.3 indicate that lower values of $F$ occur in subadiabatic layers, with reduced liquid water paths and correspondingly lower values of $\mathrm{dE}_{\mathrm{n}} / \mathrm{dz}$.

One source of uncertainty in these calculations is the value of the accommodation and condensation coefficients. Growth measurements of water droplets held in electrodynamic balance [Sageev et al., 1986] seem to indicate $\alpha \approx 1$ as used above. There is less support for the usual choice of $\beta=0.04$; recent measurements of $\beta$ [Hagen et al., 1989] show values that vary logarithmically with droplet size for droplets grown in a fast expansion chamber, with $\beta$ decreasing from 1 to 0.01 as the droplet radius increases from 1 to $15 \mu \mathrm{m}$. Hagen et al. suggest that this variation is related to increasing concentrations of surface contaminants on the older (and larger) drops. If we use their average $\beta$ for aged droplets $(\beta=0.01 \pm 7 \%)$ and recompute $\bar{G}$ we find a $30 \%$ reduction in $\overline{\mathrm{G}}$ for the conditions of Table 3 . This would increase the radiative contribution to $S_{\text {eq }}$ by $\approx$ $30-40 \%$.

The stochastic coalescence calculations presented in Section 3 show a linear relationship between the radiative exchange, $E_{d}$, and the growth rate of the predominant radius for fixed liquid water content. The growth rates shown in Figure 6 suggest that 10 min exposure to a radiative exchange of $E_{d}=7.5 \mathrm{~W} \mathrm{~m}^{2}$ would increase the predominant radius of the distributions of Table 2 by $\approx 1 \mu \mathrm{m}$. This is equivalent to a similar period spent in an updraft of $0.2-0.25 \mathrm{~m} \mathrm{~s}^{-1}$. For the initial distribution with $r_{\mathrm{vol}}=12 \mu \mathrm{m}$ in Figure 6 , this $1 \mu \mathrm{m}$ increase represents a significant portion of the growth needed to move to the more rapid stage of coalescence at $r_{\mathrm{g}}>16 \mu \mathrm{m}$. An equivalent effect can be produced by higher values of the radiative exchange and proportionally shorter residence times in the upper part of the layer.

A lower bound on the cloud top residence time can be found by assuming that the mixed layer circulation is organized, consistent with balloon and aircraft measurements of nocturnal clouds [Caughey and Kitchen, 1984; Nicholls, 1989]. These observations indicate that air parcels rise to cloud top, cool by $0.1-0.2 \mathrm{~K}$, and then descend in downdrafts spaced 100-150 m apart. Given a convective velocity scale $\mathrm{w}_{*} \approx 0.5 \mathrm{~m} \mathrm{~s}^{-1}$ (inferred from either the observations or our mixed layer model), this implies a residence time at cloud top of 3-5 min, a flux divergence of $1.6 \mathrm{~W} \mathrm{~m}^{-3}$ (or $\mathrm{E}_{\mathrm{d}} \approx 15 \mathrm{~W} \mathrm{~m}^{-2}$ ), and an $\mathrm{r}_{\mathrm{g}}$ increase of $\approx 1 \mu \mathrm{m}$ in a parcel completing this circulation.

That residence time could be significantly extended by the entrainment of inversion air, since the cloudtop entrainment instability criterion [Randall, 1980] is not met for either the moist or dry inversions of Figure 1 and Figure 2. Mixtures of inversion and cloud air will be more buoyant than surrounding cloud and will require more cooling to produce the 0.1-0.2 $\mathrm{K}$ temperature deficit of the descending plumes. As Figure 2b indicates, removal of cloud water has little impact on the value of the radiative exchange, and droplets that survive mixing with inversion air will grow as rapidly as their neighbors in adiabatic cloud, while the reduced emissivity will lower the parcel cooling rate. These mixed parcels, with reduced number concentrations, will also experience comparatively large equilibrium supersaturations in cloud-top updrafts. A parcel with an integral radius of $I=200 \mathrm{~m} \mathrm{~kg}^{-1}$, experiencing a vertical velocity of $0.1-0.2 \mathrm{~m} \mathrm{~s}^{-1}$ will produce $S_{\text {eq }}$ from $0.1 \%-0.2 \%$ from (8); from Figure 5 this would more than double the growth rate for a $20-\mu \mathrm{m}$ drop in a radiative exchange of $17.5 \mathrm{~W} \mathrm{~m}^{-2}$.

A more complete treatment of the radiative contribution to spectral broadening should consider correlations between perturbations in the radiative exchange, the vertical velocity, and the integral radius. Cooper [1989] has shown that given high (and uncorrelated) variability in I and $w$, mixing between parcels with different histories could have a substantial broadening effect on mean droplet spectra. Fluctuations in $\mathrm{E}_{\mathrm{d}}$ could act as another source of variability in $I$, as droplets residing in the upper $10-20 \mathrm{~m}$ of the cloud are exposed to significantly different values of the radiative exchange. These radiative exchange fluctuations would be particularly large for entrained parcels with low I and a few large, surviving droplets, because the removal of overlying cloud would reduce the downward flux and increase $E_{d}$. We 
have also neglected the impact of supersaturation fluctuations at the scale of individual cloud droplets. Our $\mathrm{S}_{\text {eq }}$ is the traditional far-field supersaturation, which may differ significantly from the value near the droplet surface. Srivastava [1989] has shown that this kind of supersaturation variability also has the potential to significantly broaden the drop size distribution.

We plan to calculate the cumulative impact of turbulence, entrainment, and radiative cooling on large droplets cycling through cloud using large eddy simulations. Recent work with a simple one-dimensional turbulence model, however, does suggest that condensation growth may play a significant role in the initiation of stratocumulus precipitation [Austin et al., 1995]. The results presented here indicate that radiative cooling has a similar potential, given a dry inversion and a cloud with peak $\mathrm{r}_{\mathrm{vol}}>10 \mu \mathrm{m}$.

\section{Appendix: The Equilibrium Supersaturation}

A prognostic equation for the supersaturation can be found by differentiating its definition [Pruppacher and Klett, 1978]:

$$
\frac{\mathrm{dS}}{\mathrm{dt}} \approx-\left[\frac{\mathrm{gw}}{\mathrm{R}_{\mathrm{d}} \mathrm{T}}-\frac{\mathrm{L}_{\mathrm{v}}}{\mathrm{R}_{\mathrm{w}} \mathrm{T}^{2}} \frac{\mathrm{dT}}{\mathrm{dt}}\right]+\frac{\mathrm{pR}}{\mathrm{e}_{\mathrm{s}} \mathrm{R}_{\mathrm{d}}} \frac{\mathrm{dw} \mathrm{v}}{\mathrm{dt}}
$$

where we have made the approximation $(1+S)=1$.

To obtain (8), we begin by inserting (4) into (6) and integrate over the drop size distribution:

$$
\begin{aligned}
\frac{\mathrm{dw}_{\mathrm{v}}}{\mathrm{dt}} & =4 \pi \rho_{1}\left[\mathrm{IS} \overline{\mathrm{G}}-\mathrm{IGC}_{\mathrm{k}}+\mathrm{IGC}_{\mathrm{r}}\right] \\
& -\rho_{\mathrm{l}} \frac{\mathrm{L}_{\mathrm{v}}}{\mathrm{R}_{\mathrm{v}} \mathrm{T}^{2}}\left\langle\frac{\mathrm{G}}{\mathrm{K}^{\prime}}\right\rangle\left(\frac{1}{\rho_{\mathrm{a}}} \frac{\mathrm{dE}_{\mathrm{n}}}{\mathrm{dz}}\right)_{\text {drops }}
\end{aligned}
$$

where we have used (3) to define the flux divergence due to droplets.

The overbars in (A2) denote an average weighted by the integral radius, while the angle brackets denote an average weighted by the droplet cooling:

$$
\bar{x}=\frac{\int_{0}^{\infty} x n(r) r d r}{\int_{0}^{\infty} n(r) r d r},\langle x\rangle=\frac{\int_{0}^{\infty} x n(r) F_{d}(r) d r}{\int_{0}^{\infty} n(r) F_{d}(r) d r}
$$

For the distributions of Table 2 the use of separate integral radius-weighted averages for the coefficients in (A2) introduces errors in each term of less than $2 \%$ :

$$
\begin{aligned}
\overline{\mathrm{GC}_{\mathrm{k}}} & \approx \overline{\mathrm{G}} \overline{\mathrm{C}_{\mathrm{k}}} \\
\overline{\mathrm{GC}_{\mathrm{r}}} & \approx \overline{\mathrm{G}} \overline{\mathrm{C}_{\mathrm{r}}} \\
\langle\overline{\mathrm{G}} & \approx \overline{\mathrm{G}}
\end{aligned}
$$

When we substitute (5) into (A1) we obtain for the supersaturation

$$
\begin{aligned}
\frac{\mathrm{dS}}{\mathrm{dt}} & \approx \mathrm{a}_{1} \mathrm{w}-\mathrm{a}_{2} 4 \pi \rho_{\mathrm{l}} \mathrm{I}\left(\overline{\mathrm{GS}}-\overline{\mathrm{GC}_{\mathrm{k}}}+\overline{\mathrm{GC}_{\mathrm{r}}}\right) \\
& +\mathrm{a}_{2} \rho_{1} \mathrm{a}_{3}\left\langle\frac{\mathrm{G}}{\mathrm{K}^{\prime}}\right\rangle\left(\frac{1}{\rho_{\mathrm{a}}} \frac{\mathrm{dE}_{\mathrm{n}}}{\mathrm{dz}}\right)_{\mathrm{drops}} \\
& +\frac{\mathrm{a}_{3}}{\mathrm{c}_{\mathrm{pm}}}\left(\frac{1}{\rho_{\mathrm{a}}} \frac{\mathrm{dE}}{\mathrm{dz}}\right)_{\text {total }}
\end{aligned}
$$

Solving (A5) using a multiplying factor yields (8).

We require an aerosol distribution to evaluate $\overline{\mathrm{C}_{\mathrm{r}}}$ and will make the simplifying assumption that each droplet has formed on an identical aerosol particle, consisting of ammonium bisulphate with a dry aerosol diameter of $0.2 \mu \mathrm{m}$. Observations indicate that sulphate is the principal constituent of the remote marine aerosol; observed mass distributions can be fit to a lognormal distribution with a geometric mean diameter of $0.2 \mu \mathrm{m}$ and a geometric standard deviation of 1.7 [Clarke et al., 1987; Twohy et al., 1989]. Particles with dry diameters less than $0.2 \mu \mathrm{m}$ constitute half of the total aerosol mass and $95 \%$ of the total aerosol number available as cloud condensation nuclei for this choice of distribution parameters. As the $\overline{\mathrm{C}_{\mathrm{r}}}$ values of Table 3 and Figure 4 indicate, our results are not sensitive to the choice of aerosol size.

The result given by (8) differs slightly from that presented in equation (20) of Davies [1985]. To permit a term by term comparison with his expression, we define a new average for the ratio $\left\{\mathrm{K}^{\prime} / \mathrm{D}^{\prime}\right\}$ that satisfies

$$
\begin{aligned}
\frac{\int_{0}^{\infty} n(r) F_{d}(r) d r}{\left[\frac{T_{v}}{e_{s}}\left\{\frac{K^{\prime}}{D^{\prime}}\right\}+\frac{L_{v}^{2}}{R_{v} T^{2}}\right]} & = \\
& \int_{0}^{\infty}\left(\frac{n(r) F_{d}(r)}{\left[\frac{T R_{v}}{e_{s}} \frac{K^{\prime}}{D^{\prime}}+\frac{L_{v}^{2}}{R_{v} T^{2}}\right]}\right) d r
\end{aligned}
$$

With this definition and using the expression for $F$ given in (10), (8) becones

$$
\begin{aligned}
\mathrm{S}_{\mathrm{eq}} & \approx \overline{\mathrm{C}_{\mathrm{k}}}-\overline{\mathrm{C}_{\mathrm{r}}} \\
& -\left(\left[\frac{\mathrm{a}_{4}}{(4 \pi \mathrm{IG})}\left\langle\frac{\mathrm{G}}{\mathrm{K}^{\prime}}\right\rangle\left(\frac{1}{\rho_{\mathrm{a}}} \frac{\mathrm{dE}}{\mathrm{dz}}\right)_{\text {total }}\right]\right. \\
& \left.\times\left[\mathrm{F} \rho_{\mathrm{a}} c_{\mathrm{pm}}-(1-\mathrm{F}) \frac{\mathrm{L}_{\mathrm{v}}^{2} \rho_{\mathrm{s}}}{\mathrm{R}_{\mathrm{v}} \mathrm{T}^{2}}-\left\{\frac{\mathrm{K}^{\prime}}{\mathrm{D}^{\prime}}\right\}\right]\right)
\end{aligned}
$$

Writing Davies (20) in our notation

$$
\begin{aligned}
& \mathrm{S}_{\text {eq,Davies }} \approx \overline{\mathrm{C}_{\mathrm{k}}}-\overline{\mathrm{C}_{\mathrm{r}}} \\
& -\quad\left(\left[\frac{\mathrm{a}_{6}}{\left(4 \pi \overline{\mathrm{K}} \overline{\mathrm{K}^{\prime}}\right.}\left(\frac{1}{\rho_{\mathrm{a}}} \frac{\mathrm{dE_{ \textrm {n } }}}{\mathrm{dz}}\right)_{\text {total }}\right]\right. \\
& \left.\times \quad\left[\mathrm{F} \rho_{\mathrm{a}} \mathrm{c}_{\mathrm{pm}}-\mathrm{a}_{5}(1-\mathrm{F}) \rho_{\mathrm{s}} \mathrm{L}_{\mathrm{v}}-\left(\frac{\overline{\mathrm{K}^{\prime}}}{\overline{\overline{\mathrm{D}^{\prime}}}}\right)\right]\right)
\end{aligned}
$$


There are two offsetting approximations in (A8). The extra 1/T term that appears in both the numerator and denominator of (A8) (and is also found in the droplet growth equation used by Roach [1976]) arises from the assumption that the vapor flux toward the droplet can be written in terms of the vapor density gradient $\nabla \rho_{\mathrm{s}}$. This is strictly true only under isothermal conditions. If the gradient $\nabla\left(n_{v} / n\right.$ ) (where $n_{v}$ and $n$ are the vapor number density and the total number density of moist air) is used instead, the droplet growth equation takes the form of (4), which is the same as that used by Cooper [1989] or Srivastava [1989] (W. A. Cooper, personal communication, 1993). The $5 \%$ decrease in the bracketed term in (A8) caused by the addition of the $1 / \mathrm{T}$ term is very nearly offset by the approximation that $\overline{\mathrm{K}^{\prime}} / \overline{\mathrm{D}^{\prime}} \approx\left\{\mathrm{K}^{\prime} / \mathrm{D}^{\prime}\right\}$. As a result, (A7) and (A8) agree to within 1-2\% for the droplet distributions of Table 2.

\section{Notation}

$\mathrm{a}_{\alpha} \quad$ accommodation length, $\mathrm{K}\left(2 \pi \mathrm{RM}_{\mathrm{d}} \mathrm{T}\right)^{1 / 2} /\left(\alpha \mathrm{p}\left(\mathrm{c}_{\mathrm{v}}+\mathrm{R} / 2\right)\right)$.

Kelvin term, $2 \mathrm{f}_{\mathrm{s}} /\left(\rho_{\mathrm{l}} \mathrm{r} \mathrm{R}_{\mathrm{v}} \mathrm{T}\right)$.

Raoult term, vmM/(W $\left.\left((4 \pi / 3) \rho_{1} \mathrm{r}^{3}-\mathrm{m}\right)\right)$.

molar heat capacity for water vapor.

specific heat at constant pressure for dry air. specific heat for liquid water.

specific heat at constant pressure for cloud parcel.

diffusivity of water vapor in air.

$\mathrm{f}_{\beta} \mathrm{D}$ [Fukuta and Walter, 1970].

vapor pressure.

saturation vapor pressure.

radiative exchange in band $i$.

net upward irradiance in band $i$.

upward irradiance in band $\mathrm{i}$.

downward irradiance in band $i$.

$r /\left(r+a_{\alpha}\right)$.

$r /\left(r+a_{\beta}\right)$.

surface tension.
$F_{d, i}$

$G(r)$

$\mathrm{K}$

$\mathrm{K}^{\prime}$

I

$\mathrm{L}_{\mathbf{v}}$ $Q_{a}(i, r)$

$\mathrm{m}$

$M$

$M_{d}$

$\mathrm{N}_{\mathrm{T}}$

$\mathrm{n}_{\mathrm{v}}$

$\mathrm{n}$

p

$\mathrm{r}$

$\mathrm{I}_{\mathrm{b}}$

$r_{g}$

$\mathrm{r}_{\mathrm{vol}}$

$\mathrm{R}$

$R_{\mathrm{v}}$

$\mathrm{S}$

$\mathrm{S}_{\mathrm{eq}}$

$\mathrm{S}_{\mathrm{v}}$

$\mathrm{T}$

$T_{g}$

fraction of the flux divergence due to droplets. net power emitted by droplet in band $i$.

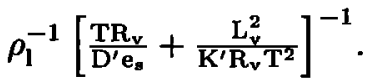

thermal conductivity of air.

$\mathrm{f}_{\alpha} \mathrm{K}$ [Fukuta and Walter, 1970]. integral radius, $I=\int n(r) r d r$.

latent heat of vaporization.

absorption efficiency in band $i$ for droplet of radius $r$.

aerosol mass.

molecular weight of aerosol.

molecular weight of dry air.

total number mixing ratio.

vapor number density.

total number density of moist air.

total pressure.

droplet radius.

normalized mass variance radius.

predominant radius.

volume mean radius.

universal gas constant.

gas constant for water vapor.

supersaturation $\mathrm{e} / \mathrm{e}_{8}-1$

equilibrium supersaturation.

dry virtual static energy.

temperature.

$T_{\mathrm{g}}$ time required for coalescence to produce $\mathrm{I}_{\mathrm{g}}=$ $50 \mu \mathrm{m}$.

v Van't Hoff factor

w vertical velocity.

$\mathrm{w}_{1} \quad$ liquid water mixing ratio.

$\mathbf{w}_{\mathbf{v}} \quad$ water vapor mixing ratio.

W molecular weight of water.

Acknowledgments. We would like to thank W. A. Cooper for pointing out the consequences of isothermal vapor diffusion discussed in the Appendix, and two anonymous reviewers for helpful suggestions. This article was typeset in $\mathrm{ITT}_{\mathrm{E}} \mathrm{X}$ using the AGUTEX JGR style and Patrick Daly's $\mathrm{AGU}^{++}$article class. The research was supported by grants from the National Research Council of Canada, the Atmospheric Environment Service, and NOAA Grant NA37RJ0203.

\section{References}

Austin, P., Y. Wang, R. Pincus, and V. Kujala, Precipitation in stratocumulus clouds: observational and modeling results, J. Atmos. Sci., 52, 2329-2352, 1995. 
Baker, M. B., Variability in concentrations of cloud condensation nuclei in the marine cloudtopped boundary layer, Tellus, Ser. B, 45, 458-472, 1993.

Barkstrom, B. R., Some effects of 8-12 $\mu \mathrm{m}$ radiant energy transfer on the mass and heat budgets of cloud droplets, J. Atmos. Sci., 35, 665-673, 1978.

Berry, E. X., and R. L. Reinhardt, An analysis of cloud drop growth by collection, I, Double distributions, J. Atmos. Sci., 31, 1814-1824, 1974a.

Berry, E. X., and R. L. Reinhardt, An analysis of cloud drop growth by collection, II, Single initial distributions, J. Atmos. Sci., 31, 1825-1831, 1974b.

Bott, A., U. Sievers, and W. Zdunkowski, A radiation fog model with a detailed treatment of the interaction between radiative transfer and fog microphysics, J. Atmos. Sci., 47, 2153-2166, 1990.

Caughey, S. J., and C. K. Kitchen, Simultaneous measurements of the turbulent and microphysical structure of nocturnal stratocumulus cloud, Q. J. R. Meteorol. Soc., 110, 13-34, 1984.

Clarke, A. D., N. C. Alquist, and D. S. Covert, The Pacific marine aerosol: Evidence for natural acid sulfates, $J$. Geophys. Res., 92, 4179-4190, 1987.

Cooper, W. A., Effects of variable droplet growth histories on droplet size distributions, I, theory, J. Atmos. Sci., 46, 1301-1311, 1989.

Davies, R., Response of cloud supersaturation to radiative forcing, J. Atmos. Sci., 42, 2820-2825, 1985.

Davies, R., and A. R. Alves, Flux divergence of thermal radiation within stratifiorm clouds, J. Geophys. Res., 94, $16,277-16,286,1989$.

Fukuta, N., and L. A. Walter, Kinetics of hydrometeor growth from a vapor-spherical model, J. Atmos. Sci., 27, 1160-1172, 1970.

Hagen, D. E., J. Schmitt, M. Trueblood, J. Carstens, D. R. White, and D. J. Alofs, Condensation coefficient measurement for water in the UMR cloud simulation chamber, $J$. Atmos. Sci., 46, 803-816, 1989.

Hocking, L. M., and P. R. Jonas, The collision efficiency of small drops, Q. J. R. Meteorol. Soc., 96, 722-729, 1970.

Jonas, P., and B. J. Mason, The evolution of droplet spectra by condensation and coalescence in cumulus clouds, $Q . J$. Roy. Met. Soc., 100, 286-295, 1974.

Jonas, P. R., The collision efficiency of small drops, $Q$. $J$. R. Meteorol. Soc., 98, 681-682, 1972.

Kovetz, A., and B. Olund, The effect of coalescence and condenastion on rain formation in a cloud of finite vertical extent, J. Atmos. Sci., 26, 1060-1065, 1969.

Nicholls, S., The dynamics of stratocumulus: Aircraft observations and comparisons with mixed layer models, $Q$. J. R. Meteorol. Soc., 110, 783-820, 1984.
Nicholls, S., A model of drizzle growth in warm, turbulent, stratiform clouds, Q. J. R. Meteorol. Soc., 113, 11411170, 1987.

Nicholls, S., The structure of radiatively driven convection in stratocumulus, Q. J. R. Meteorol. Soc., 115, 487-512, 1989.

Pruppacher, H. R., and J. D. Klett, Microphysics of Clouds and Precipitation. D. Reidel, p. 355, Norwell, Mass., 1978.

Randall, D. A., Conditional instability of the first kind upside-down, J. Atmos. Sci., 41, 402-413, 1980.

Roach, W. T., On the effect of radiative exchange on the growth by condensation of a cloud or fog droplet, $Q . J$. R. Meteorol. Soc., 102, 361-372, 1976.

Roach, W. T., and A. Slingo, A high resolution infrared radiative transfer scheme to study the interaction of radiation with cloud, Q. J. R. Meteorol. Soc., 105, 603-614, 1979.

Sageev, G., R. E. Flagan, J. H. Seinfield, and S. Arnold, Condensation rate of water on aqueous droplets in the transition regime, J. Colloid Interface Sci., 113, 421-429, 1986.

Shafrir, U., and M. Neiburger, Collision efficiencies of two spheres falling in a viscous medium, $J$. Geophys. Res., 68, 4141-4147, 1963.

Siems, S. T., D. H. Lenschow, and C. S. Bretherton, A numerical study of the interaction between stratocumulus and the air overlying it, J. Atmos. Sci., 50, 3663-3676, 1993.

Slingo, A., S. Nicholls, and J. Schmetz, Aircraft observations of marine straocumulus during JASIN, Q.J.R. Meteorol. Soc., 108, 833-838, 1982.

Srivastava, R. C., Growth of cloud drops by condensation, J. Atmos. Sci., 46, 869-887, 1989.

Twohy, C. H., P. H. Austin, and R. J. Charlson, Chemical consequences of the initial diffusional growth of cloud droplets I: Clean marine case., Tellus, Ser. $B, 41,51-60$, 1989.

P. H. Austin and Y. Wang, Atmospheric Sciences Programme, \#217 Geography, 1984 West Mall, University of British Columbia, Vancouver, B.C. V6T 122 CANADA (email: phil@geog.ubc.ca; yinong@geog.ubc.ca)

S. Siems, Department of Mathematics, Monash University, Clayton, Victoria, 3168 Australia (email: siems@cyclone.maths.monash.edu.au)

(Received July 12, 1994; revised April 5, 1995; accepted April 5, 1995.) 